\title{
Effect of the allopregnanolone and allotetrahydrodeoxycorticosteron on spike-wave discharges in the EEG of absence epilepsy rat models
}

\author{
Sebahattin Karabulut ${ }^{1}$, Ruslan Bayramov ${ }^{2}$, Keziban Korkmaz Bayramov ${ }^{2,3}$, Ahmet K. Filiz ${ }^{4}$, \\ Ahmet S. Taskiran ${ }^{4}$ and Ercan Ozdemir ${ }^{4}$ \\ ${ }^{1}$ Department of Medical Physiology, Erciyes University, Faculty of Medicine, Kayseri, Turkey \\ ${ }^{2}$ Department of Medical Genetics, Erciyes University, Faculty of Medicine, Kayseri, Turkey \\ ${ }^{3}$ Genome and Stem Cell Center, Erciyes University, Kayseri, Turkey \\ ${ }^{4}$ Department of Medical Physiology, Cumhuriyet University, Faculty of Medicine, Sivas, Turkey
}

\begin{abstract}
Absence epilepsy is a generalized nonconvulsive type of epilepsy that is characterized by spike-wave discharges (SWD) with a frequency of $2.5-4 \mathrm{~Hz}$ in the EEG. The activation of the GABAergic system in central nervous system suppresses convulsive seizures but exacerbates absence seizures. Endogenous neuroactive steroids such as $3 \alpha$-hydroxy- $5 \alpha$-pregnan-20-one (3a,5a-THPROG; allopregnanolone) and 3a,21-dihydroxy-5a-pregnan-20-one (3a,5a-THDOC, allotetrahydrodeoxycorticosteron) are GABA-A receptor-positive allosteric modulators. Finasteride which is a $5 \alpha$-reductase inhibitor can selectively block the synthesis of endogenous steroids. In this study, we compared the effects of endogenous steroids (THPROG and THDOC) on SWD by using finasteride-treated Wistar Albino Glaxo from Rijswijk (WAG/Rij) rats as a model of absence epilepsy. Wistar (WIS-THPROG and WIS-THDOC) and WAG/Rij (WAG-THPROG and WAG-THDOC) rats were divided into 4 groups $(n=8)$. After stereotactic surgical procedures, all rats were prepared for direct cortical EEG measurement. Following finasteride administration to each group, THPROG was administered to WIS-THPROG and WAG-THPROG groups, and THDOC to WIS-THDOC and WAG-THDOC groups intraperitoneally. While there was no any SWD activity detected in WIS-THPROG and WIS-THDOC groups, a significant increase in SWD count in WAG-THPROG $(p=0.012)$ and in WAG-THDOC $(p=0.012)$, and in SWD total duration in WAG-THPROG $(p=0.012)$ and WAG-THDOC groups $(p=0.011)$ were observed after steroid injection. No difference between the efficacy of THPROG and THDOC on absence seizures in WAG/Rij rats was observed.
\end{abstract}

Key words: Neurosteroids - WAG/Rij rat - Spike-wave discharges

\section{Introduction}

Despite the great interest has focused on the regulatory function of the neurosteroids in convulsive seizures over the last few years, there are scarce studies on effects of these compounds in a nonconvulsive absence epilepsy. Neurosteroids can influence upon neurotransmission, especially gamma-aminobutyric acid (GABA) neurotrans-

Correspondence to: Ruslan Bayramov, Department of Medical Genetics, Erciyes University, Faculty of Medicine, Kayseri, Turkey E-mail: dr.ruslan.bayramov@gmail.com mission which serves as a major inhibitory neurotransmitter system in the central nervous system (Reddy 2010). These neuroactive steroids are able to modulate the excitability of the brain both in synaptic and tonic inhibition way mediated by GABA-A receptors (Reddy 2011). GABA-A receptor, the major receptor for the inhibitory neurotransmitter GABA, is a chloride channel. Endogenously synthesized neurosteroids such as 3a-hydroxy-5a-pregnan-20-one (3a,5a-THPROG, allopregnanolone) and 3a,21-dihydroxy-5a-pregnan-20-one (3a,5a-THDOC) from progesterone and deoxycorticosterone are allosteric modulators of the GABA-A receptors (Kokate et al. 1994). 
Absence epilepsy is a nonconvulsive type of epilepsy, characterized by a decrease of consciousness which is accompanied by generalized, synchronous, bilateral spike and slow-wave discharge (SWD) with a frequency of $2.5-4 \mathrm{~Hz}$ in the electroencephalogram (EEG). Some absence seizures are easily controlled with antiepileptic drugs such as valproate, ethosuximide, lamotrigine and disappear during adolescence, in a term when major changes in steroid hormonal milieu happen (Loiseau et al. 1995). Whilst absence seizure pathogenesis is described in many works, the involvement of endocrine factors such as steroid hormones are not fully understood (Persad et al. 2004). Unlike convulsive seizures (Biggio and Purdy 2001), neurosteroids aggravate epileptic phenomena in absence seizures (van Luijtelaar et al. 2001).

Because of the broad-spectrum anticonvulsant potential of neurosteroids, their effects frequently investigated on seizure-induced experimental rats and mice models (Belelli et al. 1977). Although $3 \alpha, 5 \alpha-$ THPROG and $3 a, 5 \alpha-$ THDOC role in absence epilepsy is not clear, it was described that the systemic administration of progesterone increases the number and total duration of SWDs in WAG/Rij rats (Bogusława et al.1999) which is explained by GABA-mimetic action of its metabolite allopregnanolone. This seizure-exacerbating effect of progesterone is mediated by $3 \alpha, 5 \alpha$-THPROG or $3 a, 5 a-$ THDOC. These neurosteroids were antagonized by finasteride which has no effect on SWDs (van Luijtelaar et al. 2003). Finasteride, an inhibitor of $5 a$-reductase, is a drug to treat benign prostatic hypertrophy and androgenic alopecia. The mechanism of its action is the reduction of testosterone to dihydrotestosterone. Additionally, finasteride blocks the reduction of progesterone to dihydroprogesterone and deoxycorticosterone to dihydrodeoxycorticosterone (Finn et al. 2006). Thus, it is used to manipulate the level of brain neurosteroids such as $3 \alpha, 5 \alpha$-THPROG, $3 \alpha, 5 \alpha-$ THDOC in basic neurosteroid researches. $10 \mathrm{mg} / \mathrm{kg}$ dose of finasteride can decrease levels of the neurosteroids such as $3 \alpha, 5 \alpha$-THPROG and $5 \alpha$-androstane- $3 \alpha, 17 \beta$-diol in the rat brain (Higashi et al. 2008; Mukai et al. 2008). According to Bramson et al. half-life of finasteride in rats after intravenous administration calculated to be 0.9 hour (Bramson et al. 1997) and after 2 hours finasteride $(25 \mathrm{mg} / \mathrm{kg})$ administration $75 \%$ reduction of THPROG and THDOC levels in cerebral cortex was observed in rats (Concas et al. 1998). Mukai et al. (2008) showed that, rat brain THPROG levels were almost completely depleted after $1 \mathrm{~h} 50 \mathrm{~min}$ intraperitoneal finasteride $(10 \mathrm{mg} / \mathrm{kg})$ administration. Taking into account the above-mentioned reports, we think that, $2 \mathrm{~h}$ after intraperitoneal application of $10 \mathrm{mg} / \mathrm{kg}$ of finasteride, the level of neurosteroids in the rat brain will be reduced to the lowest level and finasteride concentration will be efficacious for the EEG recordings.

In this study, we aimed to compare the effects of $3 \alpha, 5 \alpha-$ THPROG and $3 \alpha, 5 \alpha-$ THDOC on spike-wave discharges in finasteride-administrated WAG/Rij rats.

\section{Materials and Methods}

\section{Animals}

Male WAG/Rij rats (supplied from the Harlan Laboratories, Radon Medical, Ankara, Turkey) and nonepileptic control Wistar albino rats (supplied from Cumhuriyet University, Experimental Research and Animal Laboratory) of 6 months of age and a body weight of 300-350 g were used as experimental subjects. Rats were housed in standard temperature-controlled $\left(21 \pm 1^{\circ} \mathrm{C}\right), 12: 12$ light-dark cycle (lights off at 7 a.m.) laboratory conditions with food and water. The rats were assigned to four groups, including eight rats in each group: first group (WIS-THPROG) - SWD to be investigated nonepileptic Wistar rats treated with finasteride and THPROG; second group (WIS-THDOC) - SWD to be investigated nonepileptic Wistar rats treated with finasteride and THDOC; third group (WAG-THPROG) - SWD to be investigated epileptic WAG/Rij rats treated with finasteride and THPROG; fourth group (WAG-THDOC) - SWD to be investigated epileptic WAG/Rij rats treated with finasteride and THDOC.

All manipulations with animals were according to the Animal Institute review committee of Cumhuriyet University, Faculty of Medicine.

\section{Experimental Protocol}

\section{Implantation of EEG electrodes}

The rats were anesthetized with an intraperitoneal xylazine (3 $\mathrm{mg} / \mathrm{kg})$ and ketamine $(90 \mathrm{mg} / \mathrm{kg}$ ) mixture. The head of each rat was placed into the stereotaxic frame. The scalp was longitudinally incised by using a surgical blade and the periosteum was removed from the surface of the cranium. The stainless-steel screw electrodes for EEG recordings were implanted into the surface of the cortex, two into the frontal region (coordinates with skull surface flat and bregma zerozero: $\mathrm{AP}=2, \mathrm{~L}= \pm 2.5$ ) and two into the parietal region (AP $=-6, \mathrm{~L}= \pm 2.5$ ) according to the Paxinos and Watson atlas. The ground electrode was placed over the cerebellum. All electrodes were stuck to the cranium with dental acrylic. The animals were allowed at least 1 week to recover from surgery. After 1 week, EEG recordings were performed both the nonepileptic Wistar control and WAG/Rij groups.

\section{Drug administration and EEG analysis}

THPROG (3a-hydroxy-5a-pregnan-20-one), THDOC (3a,21-dihydroxy-5a-pregnan-20-one) and finasteride [4-azaandrost-1-ene-17-carboxamide, $\mathrm{N}$-(1,1dimethylethyl)-3-oxo-, (5- $\alpha, 17-\beta)$ ] were purchased from Sigma-Aldrich. Both neurosteroids were dissolved in a $40 \%$ 


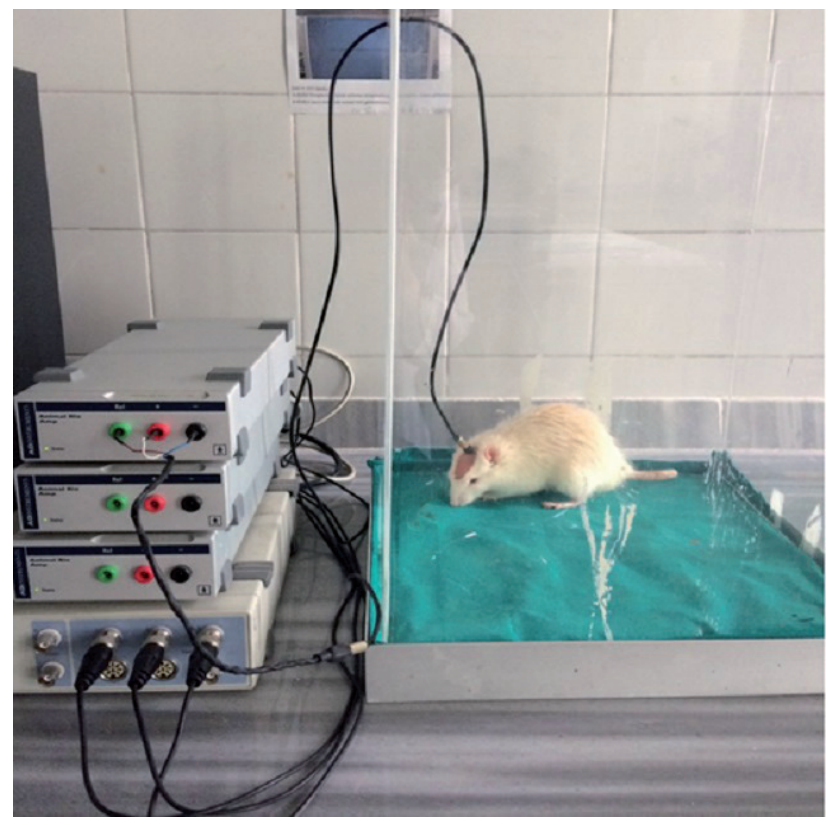

Figure 1. EEG recording process of freely moving rats.

2-hydroxypropyl- $\beta$-cyclodextrin, whereas finasteride was suspended in $1 \%$ of Tween-80. Before the experiment started, the rats were placed singly in a transparent plexiglass cage, attached to EEG leads, and were familiarized to the experimental conditions for $1 \mathrm{~h}$. All the studies were exerted between 9:00 and 15:00. The rats were connected to a multichannel amplifier (EMKA Technologies, Paris, France) by the flexible recording cable. After 1-h baseline EEG recording, the animals were injected with finasteride $(10 \mathrm{mg} / \mathrm{kg})$ and EEG was recorded for 2-h postinjection. Thereafter WIS-THPROG and WAG-THPROG rats were injected with THPROG $(20 \mathrm{mg} / \mathrm{kg})$, whereas WIS-THDOC and WAG-THDOC rats were injected with THDOC $(5 \mathrm{mg} /$ $\mathrm{kg}$ ) and EEG was recorded for 2-h postinjection. All injections were performed intraperitoneally.

\section{$500 \mu \mathrm{V}$}

\section{$20 \mathrm{~s}$}

Figure 2. EEG recordings of WIS-THPROG and WIS-THDOC groups after treatment (time mark $20 \mathrm{~s}$, amplitude calibration $500 \mu \mathrm{V}$ ).

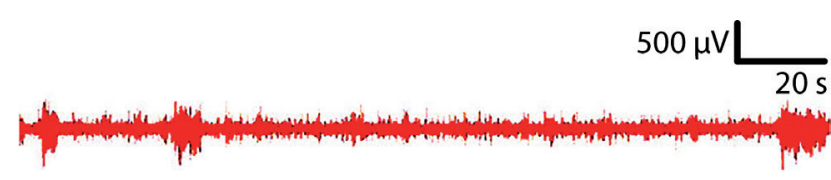

Figure 3. Basal EEG recordings of WAG/Rij rats before treatment.

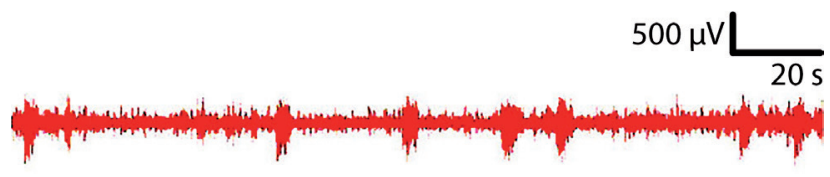

Figure 4. EEG recordings of WAG-THDOC group after treatment.

The rats were attached to a multichannel amplifier (PowerLab 4/25, ADInstruments, Inc.) via the flexible recording cable. The EEG was continuously recorded in freely moving rats (Figure ). EEGs were displayed on a computer by the LabChart7 data analysis software.

The EEGs were amplified and filtered between 1 and $100 \mathrm{~Hz}$, digitized at $200 \mathrm{~Hz}$ and stored for off-line analyses. In the present study, the SWD complex was identified as a characteristic train of sharp asymmetric large-amplitude spikes and slow waves lasting at least $1 \mathrm{~s} \mathrm{(Midzianovskaia}$ et al. 2001). The cumulative total duration and number of SWDs were detected manually in WAG/Rij rats. SWD mean duration was obtained by dividing the cumulative total duration to the number of SWDs. The EEG recordings of WIS-THPROG and WIS-THDOC groups after treatment are shown in Figure 2. Figure 3 shows basal EEG recordings of WAG/Rij rats before treatment and Figures 4 and 5 describe the EEG recordings of WAG-THDOC and WAG-THPROG groups after treatment, respectively.

Animals were euthanized by an overdose of intraperitoneal pentobarbitone sodium at the end of the experimental procedure.

\section{Statistics}

To compare the parameters between groups the independent and paired $t$ test were used as parametric and Wilcoxon paired sample-test and Mann-Whitney $\mathrm{U}$ tests were used as nonparametric tests. Results are expressed as mean $\pm \mathrm{SEM}$ / SD. Analyses were conducted by using IBM SPSS statistics 22 software with considering a $p$ value of less than 0.05 to be statistically significant.

\section{Results}

No SWD activity on cortical EEG was detected in control groups (WIS-THPROG and WIS-THDOC). Obtained other results are shown in Table 1 and 2.

The observed increase in SWD duration mean of the WAG-THPROG group after treatment with THPROG revealed to be not statistically significant in contrast with SWD total duration $(p<0.05)$ and count $(p<0.05)$ increase, which showed statistical significance. (Table 1, Figure 6)

WAG-THDOC group also not showed statistically significant increase in SWD duration mean after treatment but 


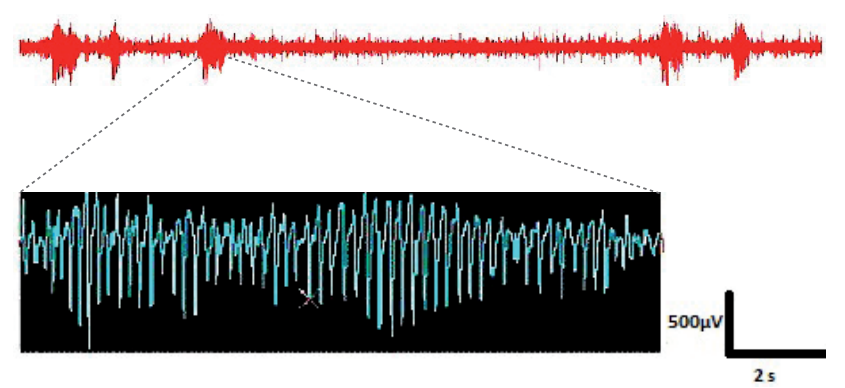

Figure 5. EEG recordings of WAG-THPROG group after treatment (time mark $2 \mathrm{~s}$, amplitude calibration $500 \mu \mathrm{V}$ ).

the detected increase in SWD total duration $(p<0.05)$ and count $(p<0.05)$ after treatment with THDOC is revealed to be statistically significant. (Table 2, Figure 7).

While comparing SWD count, SWD total durations and differences between SWD duration means of the WAG-THPROG and WAG-THDOC groups before and after treatment, no statistically significant difference was observed.

\section{Discussion}

In a study by van Luijtelaar et al. it was stated that the conversion of progesterone to allopregnanolone may play regulatory role in absence seizures in male rats under ba- sal conditions and $5 a$-reductase progesterone converts to $5 a$-dihydroprogesterone as well as to deoxycorticosterone (DOC), which is further converts to neuroactive steroid GABA agonists including THDOC (van Luijtelaar et al. 2003). So, the authors suggested a possible involvement of THDOC in absence epilepsy. We think our study sheds light onto this preconception. There is not any other study which compares the effects of THPROG and THDOC on the absence epilepsy in a rat model.

It is known that the neurosteroids increase the open duration and opening frequency of GABA-A receptor channel (Twyman and Macdonald 1992). In this case, more $\mathrm{Cl}^{-}$ions migrate into the neuron and ultimately increase hyperpolarization. So, in the presence of neurosteroids, it is more likely that GABA-A receptor channels will remain open and this inhibitory effect of GABAergic neurotransmission will be increased. This increase in GABAergic inhibition causes exacerbation of absence seizures (Banerjee and Snead 1998). This seizure increase observed after acute administration of THPROG is consistent with previous studies (Persad et al. 2002; Tolmacheva and van Luijtelaar 2007). Exacerbation of absence seizures in human was reported only in one study after progesterone administration (Grünewald et al. 1992). In our study, in finasteride-treated WAG/Rij rats systemic administration of THPROG increased SWD count and total duration which may be due to the positive allosteric modulator effect of THPROG on GABA-A receptors of the thalamocortical neurons. Evidence obtained from the study on WAG/Rij rats indicates that SWDs originate in

Table 1. SWD count, total duration and duration mean (Mean \pm SEM) in WAG-THPROG group before and after THPROG application

\begin{tabular}{|c|c|c|c|c|c|c|c|}
\hline & \multicolumn{3}{|c|}{ Before THPROG treatment } & \multicolumn{3}{|c|}{ After THPROG treatment } & \multirow{2}{*}{$p$} \\
\hline & Min & Max & Mean \pm SEM & Min & Max & Mean \pm SEM & \\
\hline SWD count & 19.00 & 38.00 & $27.38 \pm 2.17$ & 40.00 & 74.00 & $57.12 \pm 3.87$ & 0.012 \\
\hline SWD total duration & 163.64 & 321.20 & $256.33 \pm 17.35$ & 360.58 & 704.56 & $563.13 \pm 34.7$ & 0.012 \\
\hline SWD duration mean & 8.24 & 10.67 & $9.50 \pm 0.35$ & 9.01 & 11.36 & $9.91 \pm 0.28$ & 0.123 \\
\hline
\end{tabular}

SWD count and total duration show a significant increase after THPROG treatment. SWD, spike-wave discharges; THPROG, allopregnanolone.

Table 2. SWD count, total duration and duration mean (Mean \pm SEM) in WAG-THDOC group before and after THDOC application

\begin{tabular}{|c|c|c|c|c|c|c|c|}
\hline & \multicolumn{3}{|c|}{ Before THDOC treatment } & \multicolumn{3}{|c|}{ After THDOC treatment } & \multirow{2}{*}{$p$} \\
\hline & Min & $\operatorname{Max}$ & Mean \pm SEM & Min & $\operatorname{Max}$ & Mean \pm SEM & \\
\hline SWD count & 15.00 & 29.00 & $23.62 \pm 1.73$ & 40.00 & 74.00 & $62.38 \pm 7.56$ & 0.012 \\
\hline SWD total duration & 105.24 & 282.20 & $198.31 \pm 20.71$ & 204.80 & 698.76 & $525.61 \pm 69.94$ & 0.011 \\
\hline SWD duration mean & 6.93 & 9.12 & $8.23 \pm 0.32$ & 7.98 & 9.91 & $8.27 \pm 0.38$ & 0.889 \\
\hline
\end{tabular}

SWD count and total duration show a significant increase after THDOC treatment. SWD, spike-wave discharges; THDOC, allotetrahydrodeoxycorticosteron. 


\section{WAG-THPROG GROUP}

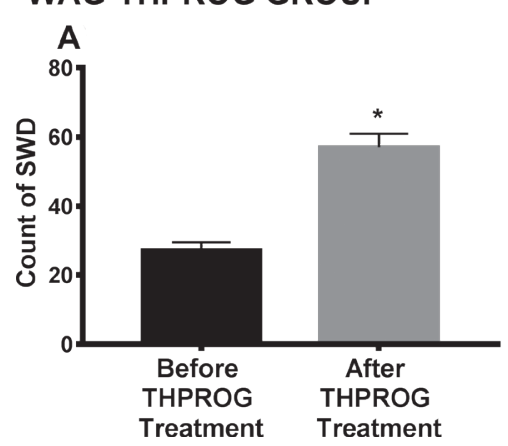

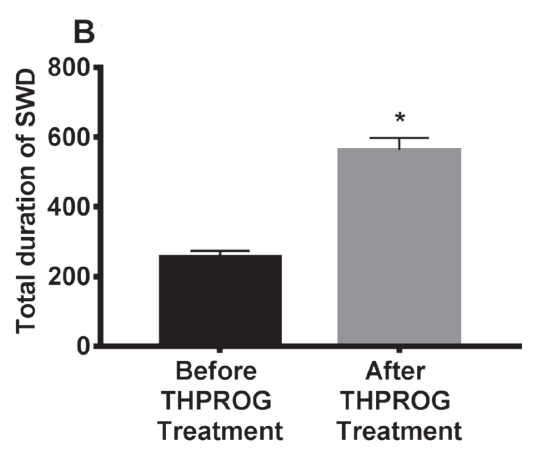

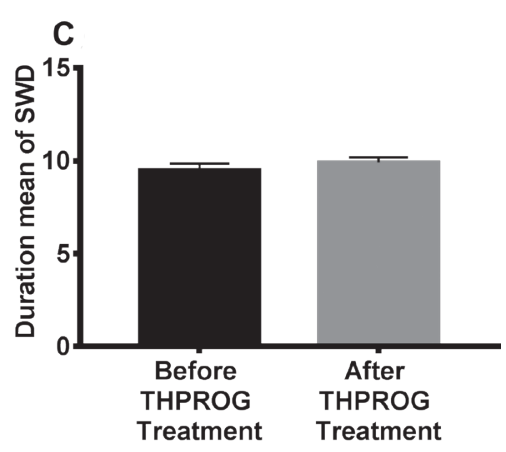

Figure 6. Comparison of slow-wave discharge (SWD) count, total duration and duration mean (mean \pm SEM) in WAG-THPROG group before and after THPROG application. SWD count and total duration show a significant increase after THPROG treatment $\left({ }^{\star} p<0.05\right)$.

the somatosensory cortex, and its activity rapidly spreads over the cortex and the thalamic nuclei (van Luijtelaar et al. 2011). Intracerebroventricular administration of the GABA-A receptor agonist muscimol enhances the number of SWDs in WAG/Rij rats (Peeters et al. 1989). Focal bilateral microinjection of neuroactive steroids such as ganaxolone and allopregnanolone into some thalamic nuclei (nucleus ventralis posterolateralis, nucleus ventralis posteromedialis) increased SWDs in WAG/Rij rats (Citraro et al. 2006). Pisu et al. showed that the cerebrocortical levels of both THPROG and THDOC had increased at an age of 6 months which observed with the worsening of the absence epilepsy in WAG/ Rij rats (Pisu et al. 2008). It was also reported in the same work that the expression of some subunits of the GABA-A receptor in thalamic relay nuclei increases in 6 months old WAG/Rij rats. So, it was concluded that an increase in tonic inhibition of thalamic relay neurons because of the increase in this subunits up-regulation may have worsened the seizures (Pisu et al. 2008). Considering all these results and the fact that the animals used in our study are 6 months old, it is not surprising that both neurosteroids increased SWD counts in WAG/Rij rats.

THDOC is a broad-spectrum steroid with proven anticonvulsant activity in studies performed on convulsive type epileptic models (Reddy 2009). THDOC activates GABA-A receptor mediated synaptic inhibition by increasing the open duration and opening frequency of GABA-A receptor channel like THPROG (Reddy 2009; Rogawski and Reddy 2004). Although THDOC is well known for its antiepileptic effect on convulsive epilepsies (Herrington et al. 2014; Shiri et al. 2015) there are scarce studies about its effect on the absence epilepsy. Banerjee et al. (1998) have shown that tetrahydrodeoxycorticosterone aggravates absence seizures in WAG/Rij rats. Schridde et al. (2004) reported that acute systemic administration of corticosterone, an adrenalderived steroid, increases SWD in WAG/Rij rats. The acute systemic administration of THDOC to finasteride-treated WAG/Rij rats in our study also resulted in a significant increase in SWD count and total duration which can be explained by the activation of the GABAergic system.

\section{WAG-THDOC GROUP}

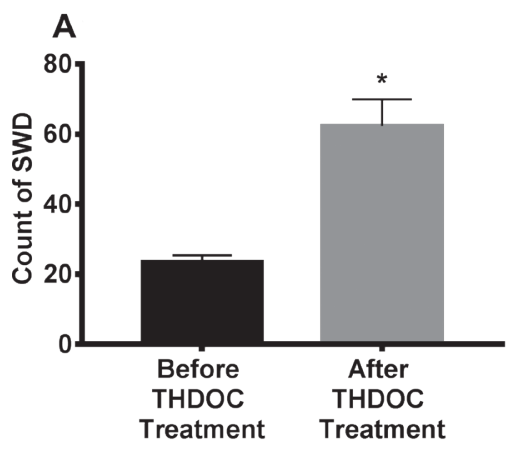

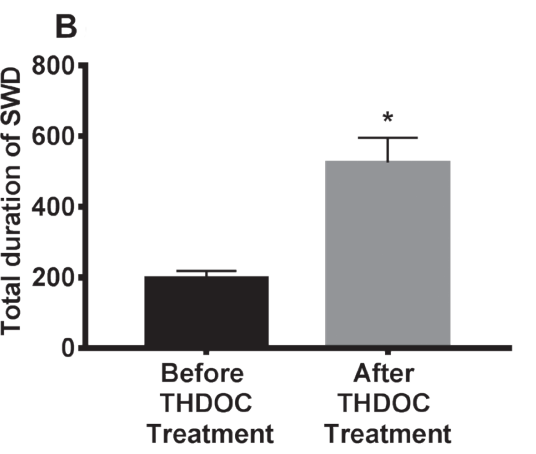

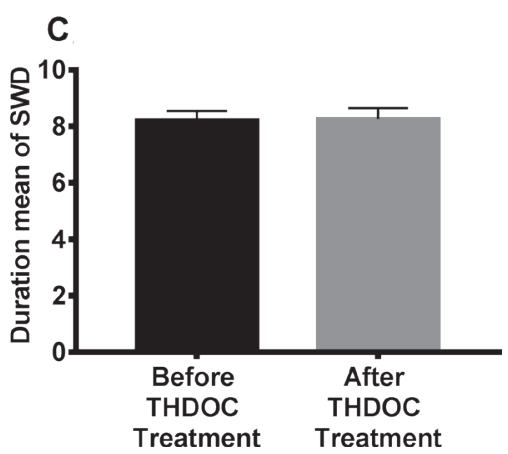

Figure 7. Comparison of slow-wave discharge (SWD) count, total duration and duration mean (mean \pm SEM) in WAG-THDOC group before and after THDOC application. SWD count and total duration show a significant increase after THDOC treatment $\left({ }^{\star} p<0.05\right)$. 
We also should not forget about anticipatory stress phenomenon due to the second injection with neurosteroids which can increase SWD activity through hypothalamic-pituitary-adrenal (HPA) axis. The HPA axis is a major control system of the neuroendocrine stress response and is a stress-mediated synthesis regulator of neuronal excitability affecting biomolecules, such as cortisol, corticosterone, and DOC (Tolmacheva et al. 2012). DOC serves as a precursor for THDOC synthesis in the brain (Kishimoto et al. 2004). So, this phenomenon may be affected THDOC level results in this study.

While comparing the effects of THDOC and THPROG on absence seizures, by statistical analyse of the increase in SWD duration mean before and after treatments no statistically significant difference was observed. This may suggest that the efficacy of this steroids in increasing the absence seizures is similar.

\section{Conclusion}

The role of neuroactive steroids that have effects on neuronal excitability in epileptic seizure susceptibility can't be denied. However, this role in seizure regulation differs according to epilepsy type. Neurosteroids such as THDOC, THPROG, which act as positive allosteric modulators of GABA-A receptors, exhibit a reduction in convulsive epileptic seizures (Samba Reddy 2017), whereas, in nonconvulsive seizures such as absence epilepsy, the situation is reversed: these steroids exacerbate seizures.

There is not a difference between the efficacy of THPROG and THDOC on absence seizures according to results obtained from this work.

Acknowledgement. This study was supported by the Cumhuriyet University Scientific Research Projects Department (CÜBAP Project No: T-505).

Conflict of interest. The authors declare that there is no conflict of interest regarding this work.

\section{References}

Banerjee PK, Snead OC (1998): Neuroactive steroids exacerbate $\gamma$-hydroxybutyric acid-induced absence seizures in rats. Eur. J. Pharmacol. 359, 41-48 https://doi.org/10.1016/S0014-2999(98)00629-3

Belelli D, Lan NC, Gee KW (1990): Anticonvulsant steroids and the GABA/benzodiazepine receptor-chloride ionophore complex. Neurosci. Biobehav. Rev. 14, 315-322 https://doi.org/10.1016/S0149-7634(05)80041-7

Biggio G, Purdy RH (2001): Neurosteroids and Brain Function. International Review of Neurobiology. (Vol. 46), New York, Academic Press
Bramson HN, Hermann D, Batchelor KW, Lee FW, James MK, Frye SV (1997): Unique preclinical characteristics of GG745, a potent dual inhibitor of 5AR. J. Pharmacol. Exp. Ther. 282, 1496-1502

Budziszewska B, Siwanowicz J, Leśkiewicz M, Jaworska-Feil L, Lasoń W (1998): Protective effects of neurosteroids against NMDA-induced seizures and lethality in mice. Eur. Neuropsychopharmacol. 8, 7-12 https://doi.org/10.1016/S0924-977X(97)00037-0

Budziszewska B, Van Luijtelaar G, Coenen AM, Leśkiewicz M, Lason W (1999): Effects of neurosteroids on spike-wave discharges in the genetic epileptic WAG/Rij rat. Epilepsy Res. 33, 23-29 https://doi.org/10.1016/S0920-1211(98)00067-9

Citraro R, Russo E, Di Paola ED, Ibbadu GF, Gratteri S, Marra R, De Sarro G (2006): Effects of some neurosteroids injected into some brain areas of WAG/Rij rats, an animal model of generalized absence epilepsy. Neuropharmacology 50, 1059-1071 https://doi.org/10.1016/j.neuropharm.2006.02.011

Concas A, Mostallino M, Porcu P, Follesa P, Barbaccia M, Trabucchi M, Purdy RH, Grisenti P, Biggio G (1998): Role of brain allopregnanolone in the plasticity of $\gamma$-aminobutyric acid type A receptor in rat brain during pregnancy and after delivery. Proc. Natl. Acad. Sci. 95, 13284-13289 https://doi.org/10.1073/pnas.95.22.13284

Finn DA, Beadles-Bohling AS, Beckley EH, Ford MM, Gililland KR, Gorin-Meyer RE, Wiren K M (2006): A new look at the $5 \alpha$-reductase inhibitor finasteride. CNS Drug Rev. 12, 53-76 https://doi.org/10.1111/j.1527-3458.2006.00053.x

Gasior M, Carter RB, Goldberg SR, Witkin JM (1997): Anticonvulsant and behavioral effects of neuroactive steroids alone and in conjunction with diazepam. J. Pharmacol. Exp. Ther. 282, 543-553

Grünewald R, Aliberti V, Panayiotopoulos C (1992): Exacerbation of typical absence seizures by progesterone. Seizure 1, 137-138 https://doi.org/10.1016/1059-1311(92)90012-P

Herrington R, Lévesque M, Avoli M (2014): Neurosteroids modulate epileptiform activity and associated high-frequency oscillations in the piriform cortex. Neuroscience 256, 467-477 https://doi.org/10.1016/j.neuroscience.2013.10.025

Higashi T, Yokoi H, Nagura Y, Nishio T, Shimada K (2008): Studies on neurosteroids XXIV. Determination of neuroactive androgens, androsterone and $5 \alpha$-androstane- $3 \alpha, 17 \beta$-diol, in rat brain and serum using liquid chromatography-tandem mass spectrometry. Biomed. Chromatogr. 22, 1434-1441 https://doi.org/10.1002/bmc.1078

Kishimoto W, Hiroi T, Shiraishi M, Osada M, Imaoka S, Kominami S, Igarashi T, Funae Y (2004): Cytochrome P450 2D catalyze steroid 21-hydroxylation in the brain. Endocrinology 145, 699-705 https://doi.org/10.1210/en.2003-1109

Kokate TG, Svensson B, Rogawski MA (1994): Anticonvulsant activity of neurosteroids: correlation with gamma-aminobutyric acid-evoked chloride current potentiation. J. Pharmacol. Exp. Ther. 270, 1223-1229

Loiseau P, Duche B, Pédespan JM (1995): Absence epilepsies. Epilepsia 36, 1182-1186 
https://doi.org/10.1111/j.1528-1157.1995.tb01060.x

Midzianovskaia IS, Kuznetsova GD, Coenen AM, Spiridonov A M, van Luijtelaar EL (2001): Electrophysiological and pharmacological characteristics of two types of spike-wave discharges in WAG/Rij rats. Brain Res. 911, 62-70 https://doi.org/10.1016/S0006-8993(01)02705-6

Mukai Y, Higashi T, Nagura Y, Shimada K (2008): Studies on neurosteroids XXV. Influence of a 5alpha-reductase inhibitor, finasteride, on rat brain neurosteroid levels and metabolism. Biol. Pharm. Bull. 31, 1646-1650 https://doi.org/10.1248/bpb.31.1646

Peeters B, Van Rijn C, Vossen J, Coenen A (1989): Effects of GABA-ergic agents on spontaneous non-convulsive epilepsy, EEG and behaviour, in the WAG/RIJ inbred strain of rats. Life Sci. 45, 1171-1176 https://doi.org/10.1016/0024-3205(89)90505-5

Persad V, Cortez MA, Snead OC (2002): A chronic model of atypical absence seizures: studies of developmental and gender sensitivity. Epilepsy Res. 48, 111-119 https://doi.org/10.1016/S0920-1211(01)00319-9

Persad V, Wong T, Cortez MA, Wang YT, Snead OC (2004): Hormonal regulation of atypical absence seizures. Ann. Neurol. 55, 353-361 https://doi.org/10.1002/ana.10831

Pisu MG, Mostallino MC, Dore R, Mura ML, Maciocco E, Russo E, De Sarro G, Serra M (2008): Neuroactive steroids and GABAA receptor plasticity in the brain of the WAG/Rij rat, a model of absence epilepsy. J. Neurochem. 106, 2502-2514

Reddy DS (2009): The role of neurosteroids in the pathophysiology and treatment of catamenial epilepsy. Epilepsy Res. $85,1-30$ https://doi.org/10.1016/j.eplepsyres.2009.02.017

Reddy DS (2010): Neurosteroids: Endogenous role in the human brian and therapeutic potentials. Prog. Brain Res. 186, 113 https://doi.org/10.1016/B978-0-444-53630-3.00008-7

Reddy DS (2011): Role of anticonvulsant and antiepileptogenic neurosteroids in the pathophysiology and treatment of epilepsy. Front. Endocrinol. 2011, 2:38 https://doi.org/10.3389/fendo.2011.00038

Rogawski MA, Reddy DS (2004): Neurosteroids: endogenous modulators of seizure susceptibility. In: Epilepsy: Scientific
Foundations of Clinical Practice. (Eds. Rho JM, Sankar R, Cavazos J), pp. 319-355, Marcel Dekker, New York Samba Reddy D (2017): Sex differences in the anticonvulsant activity of neurosteroids. J. Neurosci. Res. 95, 661-670

Schridde U, van Luijtelaar G (2004): Corticosterone increases spike-wave discharges in a dose-and time-dependent manner in WAG/Rij rats. Pharmacol. Biochem. Behav. 78, 369-375 https://doi.org/10.1016/j.pbb.2004.04.012

Shiri Z, Herrington R, Lévesque M, Avoli M (2015): Neurosteroidal modulation of in vitro epileptiform activity is enhanced in pilocarpine-treated epileptic rats. Neurobiol. Dis. 78, 24-34 https://doi.org/10.1016/j.nbd.2015.03.020

Tolmacheva EA, Oitzl MS, van Luijtelaar G (2012): Stress, glucocorticoids and absences in a genetic epilepsy model. Horm. Behav. 61, 706-710 https://doi.org/10.1016/j.yhbeh.2012.03.004

Tolmacheva EA, van Luijtelaar G (2007): The role of ovarian steroid hormones in the regulation of basal and stress induced absence seizures. J. Steroid Biochem. Mol. Biol. 104, 281-288 https://doi.org/10.1016/j.jsbmb.2007.03.017

Twyman R, Macdonald R (1992): Neurosteroid regulation of GABAA receptor single-channel kinetic properties of mouse spinal cord neurons in culture. J. Physiol. 456, 215-245 https://doi.org/10.1113/jphysiol.1992.sp019334

van Luijtelaar G, Budziszewska B, Jaworska-Feil L, Ellis J, Coenen A, Lasoń W (2001): The ovarian hormones and absence epilepsy: a long-term EEG study and pharmacological effects in a genetic absence epilepsy model. Epilepsy Res. 46, 225-239 https://doi.org/10.1016/S0920-1211(01)00277-7

van Luijtelaar G, Budziszewska B, Tetich M, Lasoń W (2003): Finasteride inhibits the progesterone-induced spike-wave discharges in a genetic model of absence epilepsy. Pharmacol. Biochem. Behav. 75, 889-894 https://doi.org/10.1016/S0091-3057(03)00162-X

van Luijtelaar G, Sitnikova E, Luttjohann A (2011): On the origin and suddenness of absences in genetic absence models. Clin. EEG Neurosci. 42, 83-97 https://doi.org/10.1177/155005941104200209

Received: April 28, 2017

Final version accepted: September 1, 2017 